\title{
Effective Employment Screening Practices
}

by Garnet Frankenfield and Brian H. Kleiner

Why Companies Should Screen Candidates

"Hiring a new employee is like a box of chocolates: you never know what you are going to get" [17,p.10].

The days of applications and gut feelings alone are over. Interviewing exclusively is not good enough; for every question the interviewers asks there is a book out there which tells the job seeker how the question can best be answered. There are dozens of books on how to impress the interviewer which even include pat answers. These days you can not even pick up a magazine without running across an article about "How to play the interviewing game and win". Job seekers are onto the interviewing game and are prepared, some have even been groomed for interviews. "Those applicants who are particularly adept at projecting a favourable impression in an interview, namely job-hoppers and sociopaths have an almost uncanny ability to tell interviewers exactly what they want to hear" $[17$, p.11]. It is not that interviewing is not helpful, it is just that it is not the single best way. How often have you interviewed and hired someone who did not live up to their promises of knowledge, capability, and willingness.

Because so many companies have downsized a greater emphasis has been put on finding and keeping the best people. The time and money spent reviewing resumes and applications, interviewing, training, and advertising will all have been wasted if the new employee does not work out or does not stay. "The cost of recruiting and hiring a new employee has risen $75 \%$ in the past five years, and there are costs to firing too, says Craig Aberie, CEO of MicroBiz" $[10$, p.65]. "Generally, turnover cost is estimated at about one-third of an annual salary" 3 , p.12]. Putting the right person in the right job is cost efficient.

The damage done by a single hiring mistake can be severe and small businesses stand to suffer the most. Each employee of a small business accounts for a larger part of that business' activities. Therefore, if an employee of a small company does not perform adequately then that employee can effect the success of the whole company. Unfortunately, small businesses are more likely to make hiring mistakes. Small companies are more likely to hire a friend of a friend because they can be trusted, not because they possess the skills required to perform the job[2].

Workplace violence, drugs, and negligent hiring lawsuits are the types of issues today's employers are facing $[6$, p.85].

'The U.S. Chamber of Commerce indicates that about one-third of all business failures can be attributed to employee theft. Furthermore, the Justice Department estimates that internal theft costs US businesses more than $\$ 60,000,000,000$ a year"

$[17$, p.10]. An effective screening method is the best protection for employers.

\section{Companies That Utilise A Screening Process}

Companies who have been burned by poor hiring say they will no longer rely solely on resumes, interviews, and references. American Honda has an approach called "process-oriented, common-sense approach to interviewing and hiring". The traditional way to hire a person was based on the personality of the candidate and the intuition of the employer. "Honda is using a five step interviewing process that begins with an analysis of the skills needed for a position and continues through the rating of the applicant's skills following the interview. Honda's five step interview process for screening candidates consist of Complete Skills Analysis, Select Skill Definitions, Develop Questions, Conduct Interview, and then Rate Skills" [3, p.12].

'Recruitment is seriously viewed as a competitive activity in its own right. At Microsoft, for instance, chairman Bill Gates regards recruitment as one of his top priorities and devotes a surprising amount of time to it'[19, p.63].

Finding and keeping good employees is the favoured approach by Proctor and Gamble, which is known for "develop-and-promotion-from-within culture, in which high-calibre graduates are taken on, developed, and groomed for better things within the company". In addition, Proctor and Gamble will not reveal how they go about hiring or grooming their employees. They regard their techniques as a source of a competitive advantage $[19, \mathrm{p} .63]$. 
"Smart recruiting also carries important public relations and marketing overtones. The best thing we can do for competitors is to hire badly, says David Pritchard, Microsoft's Seattle-based director of human resources"'[19, p.63].

"Cole of JP Morgan talks in terms of the three C's: clients, competitors and colleagues". Rejected candidates may go on to work for the competition, become a customer, or influence other potential recruits. Hence, JP Morgan wants unselected candidates to walk away with a good feeling about JP Morgan even if they did not get the job[19, p.64].

"Caliper's Weinstein, whose company has administered over a million 'personality assessments', concurs that 'one of the biggest mistakes a company can make is being overly reliant on any one element in the hiring process. If we base the whole decision to hire on an interview, or a resume, or work experience, or a test, or a reference, or appearance- any of those things - it's going to be wrong. The goal is to get all those data points to sing in unison"'[2, p.26].

\section{When Does The Screening Process Start}

The screening process should start even before you have the need for a new employee. The company should invest some time in deciding what kind of person it needs, what position will the new employee fill, what skills are needed for the position, and which skills they are willing to train the new employee. You might be thinking, "What does this have to do with screening applicants". Well, what good will it do to screen applicants if you do not know what you are screening for?

Only when a company knows the kind of employee they want, the position the new employee will hold, and the skills the new employee needs to possess, will they be ready to recruit new employees. This may seem elementary to some, but you would be surprised how many businesses have not already done this process. Small companies are especially needy in this area. They like to just hire a friend of a friend without even having a job description for the new person; because there is too much work for the current employees. Small and new companies are most likely to experience rapid growth and if they are not ready it will be a disaster.

\section{Placing An Ad}

"Instead of placing an ad in the paper solely for the purpose of praising the firm's virtues, you should try wording it like this, 'Looking for an honest, dependable, and productive person with a clean drug history'. Someone who has just been fired for dishonesty or drug use on the job would probably be reluctant to answer such an ad" [7, p.7].

\section{An Effective Screening Process Involves}

An effective employment screening process involves a collection of the following; an application form with substance, interviews, aptitude and/or honesty testing, reference checks, drug testing, and background checks. Each company should have a screening process that has been designed for their hiring needs.

\section{"Malcolm Wheatley of the UK has a list of How to Recruit and Retain:}

1. Drive the recruitment process from the top. Do not leave it to HR professionals: if people are a business's greatest asset, get personally involved.

2. Target particular institutions and sources of new recruits; make clear the sort of business you are, and the sort of culture you have so people of the right calibre put themselves forward, thus improving the hit rate of the recruitment process.

3. Recruit for the long term: hire bright people with potential to grow. Learn from those who leave why they chose to go.

4. Be cautious about an over reliance on psychometric tests as a substitute for tough interviews with potential peers and superiors. The best people to judge new recruits are those already out there doing the job.

5. Case interviews and behavioural event interviews can tell a lot: it is not the correct answer so much as the right thought processes which count.

6. Think of the impression your recruitment process makes on rejected candidates and regard them as potential ambassadors for the business" [19, p.64]. 


\section{Applications}

It may seem evident to you that candidates should come in and fill out an application. The key is to use an application form with substance, not one of those out dated applications which might even be illegal. "A properly designed application form can disclose relevant work attitudes and qualifications (without violating state and Federal employment laws), and actually serve as a screening tool in itself' [7, p.7]. You could even use this opportunity to get more information about the applicant; you could ask the applicant to take a test, say in basic math or logic.

\section{The Interview Process}

Because so many companies have downsized a greater emphasis has been put on finding and keeping the best people. Companies are spending heavily on training their managers how to interview and hire the best people.

"Boggis-Rolfe regards an interview as an opportunity to explore beyond the curriculum vitae and find out what candidates have actually done (as opposed to the positions they have held) and make an intelligent assessment of the candidate's personality and likely fit within an organisation" [17, p.62]

Types of interviews. In an oral "situational interview" candidates are presented with job related scenarios and then asked to explain how they would respond. "The situational interview is predicated on the theory that there is a powerful relationship between what people say they will do in a specific situation and what they actually do. However, this relationship is frequently not as strong as one might like. Therefore, in the second part of the interview, candidates are asked how they performed when exposed to similar situations in the past" [13, p.35].

"What interests recruiters such as Microsoft, JP Morgan, and Bain is candidates' performance during case interviews or behavioural event interviews". What is a case interview or a behavioural event interview? They are interviews that put candidates in a situation which they do not know the answer, to see how they react, think, and solve the problem. For example, "Bain and JP Morgan ask a question like, how would you establish how many petrol stations there are in London?" These companies are not concerned with how many gas stations are in London but how a candidate would go about solving such a problem. These companies want to evaluate the candidate's problem solving skills when faced with something unfamiliar. In addition, these companies ask questions "based around work-related scenarios - the behavioural event: "A client wants to do such and such..... What do you do?" The key is to see how people use deductive reasoning and common sense along with problem solving skills. These companies "are looking for people who have the right skills, and who share their values: a problem-solving mentality and a passion for getting results" [19, p.64].

\section{Testing Candidates}

More and more businesses have learned to test before they hire. Even Taco Bell makes applicants take a 30 minute test; they want to make sure that the applicant can read a sentence, will not steal, and will not leave after their first pay cheque [8, p.106]. "And, auto workers are tested for skills such as reading, mathematics, and mechanical dexterity. The Systems Consulting Group, a systems integrator that hired over a 150 new employees in one year (1985), requires candidate to "submit to a two-hour logic and analytical-skills test. Which assesses an applicant's problem-solving abilities, attention to detail, and concentration" [10, p.66]. It is important to look for both a good interview and high test score from a hiree.

Research and knowledge are needed to know what a test should measure. "Business also found that testing is something of a protection in "discrimination" lawsuits, since everybody takes the same test and the scores are there for judges and juries to see" $[8, p .106]$.

Because of all the publicity about employee lawsuits, it is almost impossible to get the needed information on possible hires from litigation-shy former employers, and, a resume and/or application is not enough. MicroBiz an "\$8.8-million management-software developer uses an outside agency to administer IQ, personality, and drug test, and to run checks on all prospective employees' credit histories, criminal records, and motorvehicles-registry records. The company pays the agency roughly $\$ 1,000$ a hire and has invested $\$ 25,000$ this year alone (1995), mostly in interview training. MicroBiz appears to be getting results: two years ago turnover was $100 \%$; today it's $35 \%$ " [10, p.66].

Different types of tests. There are a number of tests that measure honesty. These tests are "available from companies such as Reid Psychological Systems, Chicago; London House, Rosemont, Ill.; CHC Forecast Inc., Stanfordville, N.Y.; Wonderlic, Libertyville, Ill.; and Lousig-Nont \& Associates, Las Vegas. These tests are good indicators of who will and who will not be an honest employee" [11, p.83]. 
A company should inform candidates that they will be asked to take a written honesty test after the human resource department has reviewed their applications and feel that they may qualify for the job. "It is recommended that companies use a scientifically validated, reliable, and time-tested honest and integrity test developed by a reputable company" [7, p.7]. "Anotgher thing to look for is a validity scale, or a 'faking scale'. These are questions within the test designed to determine if the person was trying to beat the test" [11, p.83\&84]. "Before using any test, companies should ask the publisher for a copy of their study that demonstrates the instruments follows all Equal Employment Opportunity Commission guidelines and does not discriminate" [7, p.7]. "These tests predict not just honesty, but good employees. The test actually measures the work ethic, which includes honesty, but it is more than that. A person with a good work ethic believes that to work is good. People should get some self-satisfaction out of work" [11, p.83\&84].

Here is an example of a question to "find out if the candidates sees themselves in control of their lives, or if they believe things just happen. You ask a question like, 'Why do people succeed?' You give a choice: They get lucky, they know somebody, they work hard, they get an education. The answers; work hard and get an education show that the candidate accepts responsibility" [8, p.109].

In-basket exercises are paper and pencil exercises. The candidates are given a situation and several corresponding answers. Then the candidate has to pick and order the top three answers for each situation. The best and worst responses to questions and the optimum order of responses for each question have been decided before the company administers the exercise [13].

Play a game to uncover the real person inside the candidate. It may sound silly, but that is what Wilton Corp.; a \$65-million industrial-products manufacturer in Platine, Ill. does. Prospective employees are invited to the company for a day to play games which Wilton words as an "experiential education exercise": Then the human resources department must talk with the employees of the department which the prospective employee will work to find out what behaviours are critical for success in that position. Next an exercise is chosen that draws forth the desired behaviour. "The games usually involve completing a task (like transferring marbles down a series of troughs into small cardboard boxes) in a team setting. The other players include future co-workers. If candidates feel uncomfortable about the exercise, that is revealing. 'Coming into a new situation, introducing yourself, and working with a group to solve a problem - that is an analogue for the first day', says Kevin Roche, manager of human-resources". This game playing has actually cut out potential employees. "For example, an applicant for the position of operations manager, Roche says, was leading a team through one of the activities and deliberately overlooked a mistake in order to finish the task more quickly. He was ruled out because his quality standards were not up to snuff, 'it is hard to hide when you are playing a game', says Roche. Our natural behaviours come through" [12, p.120].

Role playing, places the candidates in a situation that they will actually encounter on the job. A situation should be selected for its ability to help management differentiate between desired and undesired performances. These exercises reveal the candidates' job related behaviour and allows patterns and chartacteristics to emerge. All candidates are given the same job related scenario. The scenario should be predetermined and touch on several dimensions of the job. The candidates are read a brief statement which explains the context and role they will be assuming. In addition, the candidates are told to rely on their own best judgement. A company employee and the candidate act out the scenario which consist of problems that are likely to occur on the job. The candidates are then rated on their performance [13].

The assessment centre approach was developed by the U.S. military during World War II, but was not used in the private sector until the 1950's by AT\&T. Developing an assessment centre will increase hiring cost but the end result may be worth it [13].

To develop an assessment centre the company must start by performing a systematic analysis of the job; which involves talking with experts, consulting literature, and examining the standard operating procedures of the job. A list must be made of all job related skills, duties, and practices required. Scenarios which will expose specific behaviours need to be defined. Establish the best response and the errors typically made for each scenario. By establishing the best and worst responses you create a scale to judge the performance of each aspect of the job. All candidates must be measured by the same standards [13].

"There are rules and regulations regarding assessments centres. The 17th International Congress on Assessment Centre Methods, which assembled in May 1989 came up with the following guidelines for developing an assessment centre: 
1. Job analysis. A job analysis must be done to determine the job's dimensions, as well as the knowledge, skills, and abilities required for the job.

2. Observation. Each candidate must be analysed by multiple trained assessors usually two per candidate and the observation must be behaviourally based and classified into relevant categories.

3. Exercises. The exercises developed must identify characteristics. These activities may be called dimension-focused exercises. For example, where "communications skills" are identified as an important dimension, it is necessary to design activities that call for the candidate to use written and verbal communications, such as report writing.

4. Multiple techniques. Multiple assessment techniques must be used to yield multiple observational opportunities for the various job dimensions. The techniques may include tests, interviews, role plays, group activities, in-basket exercises, and simulations.

5. Recording. A standardised procedure must be established when assessors record observed behaviours of the candidates for each exercise. Such a procedure may include behavioural checklists, rating scales, or handwritten notes.

6. Pooled observation. Assessors must pool their observations to yield a total score for each candidate.

* Those considering developing an assessment centre should contact a qualified human resource consultant with experience in assessment development" [13, p.35].

\section{Drug Testing}

More companies are electing to do drug testing on existing employees and new hires. Drug testing creates a safer environment, a higher quality work force, and reduces medical insurance, workers compensation, and liabilities. "Some information indicates that drug users consume 7-8 times the medical benefits of non-users". Several companies do drug testing because it is required by the Government, other companies do drug testing to attract higher quality workers. "However, there are some things to watch out for, such as making sure the lab is following all the correct procedures, and making sure, at the company end, that there is no opportunity to 'tamper' with samples" [4, p.70].

Sure there are products on the market that are "supposed to" make a positive drug test result but the chemicals in these products are spotted in the testing process. As for drinking lots of water, it only dilutes the amount of drugs in the urine; so, the drugs are still detected or another sample is requested [4].

"About 5 per cent of a typical company's specs would be positive. As an example, take cocaine. Of that five per cent, 25-30 per cent would be cocaine. That means 1 out of each 100 would be cocaine" [4,p.70].

\section{Background and Reference Checks}

Verify all information on resumes and applications and check references. Unfortunately this is easier said than done. Employers can not and will not say much for fear of a lawsuit. Candidates are not going to list the employers who will say bad things about them, who they stole from, or who fired them. Candidates will give only the references which they know will speak highly of them.

There is an array of software on conducting background checks and investigation which can uncover criminal activity and reduce losses. The ASIS Security Resources 1996-1997 catalogue, has software that covers everything from Identifying Lies in Disguise, by Wendell C. Rudacille to How to do Financial Asset Investigations, by Ronald L. Mendell. If you want more information call ASIS Customer Services (703) 522-5800 [1].

"Robert LoPresto, co-author of The Reference Checking Handbook (Society for Human Resource Management, 800-444-5006, \$20) offers these tips:

1. Obtain job candidates' written permission to check references. Consider asking applicants to sign a liability waiver for employers who give reference-checking information.

2. 'Gather as much historical factual data as possible' from the employee and past employers. 'Past success predicts future success'. 
3. Beware of inaccuracies. 'What we look for more than anything else is integrity. It is the number one criteria for success'.

4. Talk to former supervisors, peers, and if appropriate, subordinates. 'You want to find out what they are like to work with and for' $[9, \mathrm{p} .120]$.

\section{Conclusion}

A candidate may seem right for the job but they could be just well rehearsed. Candidates are better prepared for interview thanks to the many books on "The Best Answers to the Hardest Question Used by Interviewers". Getting the scoop on a candidate from a former employer is practically impossible. Employers can not and will not say much for fear of a lawsuit. What is a company to do? A comprehensive employment screening package is a companies best bet; "after rejecting low test scores and subjecting the rest to employment verification, background checks and drug tests, you are generally down to $30 \%$ to $40 \%$ of the original group" [8, p.106]. A company's comprehensive employment screening package should include a compilation of the following: an application form with "teeth", interviews, testing, reference checks, and back ground checks. If a company feels that they can not handle the task then they should use an outside company to do the job.

Take the time to do the necessary research because a bad seed is costly. Current articles and information on the internet are best. The book store's computer (Crown Books) listed a dozen books on the topic of hiring, yet they did not have one of the books on the shelves. And, the books at the library are too basic or out dated. The software packages looks good; but, none of them were reviewed for this article because it was not in the research budget.

\section{References}

1. ASIS Security Resources 1996-1997, Smythe, Inc., New York, 1996.

2. Barrier, Michael, "Hiring The Right People", Nation's Business, June 1996, pp.8-27.

3. "Corporations Hone Interview Skills", USA Today, Dec. 1996, pp.11-12.

4. "Drug Testing: Devil in Details", Security, Feb. 1996, p.70.

5. Fear, Richard F., The Evaluation Interview, McGraw-Hill, Inc., New York, 1978.

6. "Firms Outsourcing More Screening Tools in Hiring", Security, Feb. 1997, p.85.

7. “Five-Step Approach Means Better Workers", USA Today, Dec. 1995, pp.7-8.

8. Flint, Jerry, “Can You Tell Applesauce From Pickles?”, Forbes, 9 Oct. 1995, pp.106-108.

9. “Getting Information—Safely”, Inc., Dec. 1995, p.120.

10. Gruner, Stephanie, “Once Burned”, Inc., 15 Oct. 1995, pp.65-66.

11. Hodgson, Karyn, “The Truth About Honesty Tests”, Security, April 1996, pp.83-84.

12. "It's How You Play the Game", Inc., Dec. 1995, p.120.

13. Leeds, Peter J., and Burroughs, Wayne, "Finding the Right Stuff", Security Management, March 1997, pp.34-43.

14. Mercer, Michael W., Hire The Best...And Avoid The Rest, AMACOM, New York, 1993.

15. Miller, William H., "The Future? Not Yet”, Industry Week, 17 April 1995, p.73.

16. O’Mara, Deborah L., “Help Yourself To Background Checks”, Security, March 1997, pp.91-92.

17. “Old Interview Methods Proving Ineffective”, USA Today, Dec. 1996, pp.10-11.

18. Pospisil, Vivian, “Measure of Success”, Industry Week, 5 Feb. 1996, p.11.

19. Wheatley, Malcolm, “Talent Spotters", Management Today, June 1996, pp.62-64. 